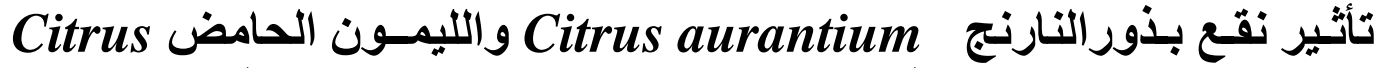

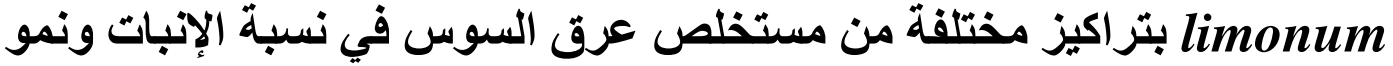 الثتنلات
}

\section{فاطمة خيون محمد الوائلي}

$$
\begin{aligned}
& \text { قسم شؤون الديوان، رئاسة جامعة بغداد. } \\
& \text { استلام البحث 2015/4/28 } \\
& \text { قبول النشر 16/ 2015/9 البحت }
\end{aligned}
$$

\section{(c) $(1) \Theta \Theta$}

This work is licensed under a Creative Commons Attribution-NonCommercialNoDerivatives 4.0 International Licens

أُجري هذا البحث تحت ظروف الظلة الخشبية التابعة لمشتل جامعة بغداد للموسم 2013 بهدف دراسة تأثير

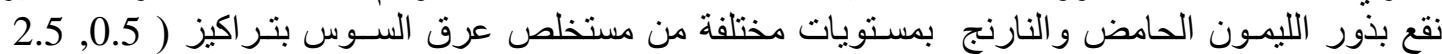

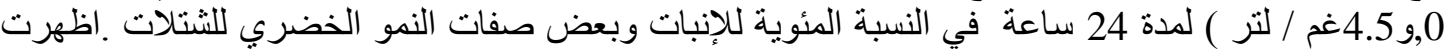
النتائج تفوق شتنلات النارنج وبتركيز نقع لمستخلص عرق التهات السوس

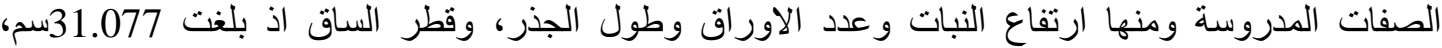

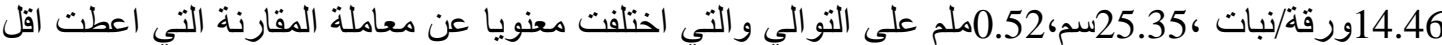
يتضيح بأن لمستخلص عرق السوس تأثثراً بايولوجياً مشابهاً لتأثير الجبرلين في أنبات بذور الليمون الحامض

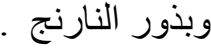

الكلمات المفتاحية : مستخلص عرق السوس،النارنج،الليمون الحامض

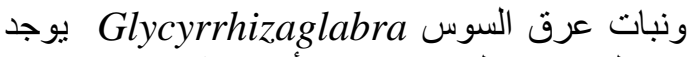
في العراق حول الانهار وبدأت تنتشر زراعناعنه في

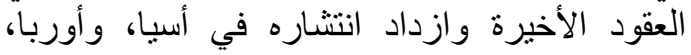

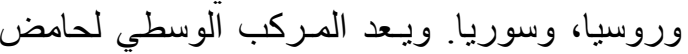
الميفالونك (البادئ في بناء الجبرلين في النبات ويسلكي الكئي

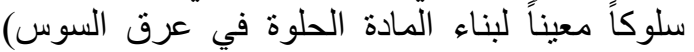

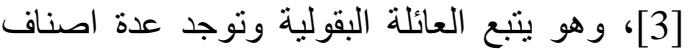
منه Grandulif جذور هذا النبات بحلاوة عصار اتها لاحتو ائها مواد

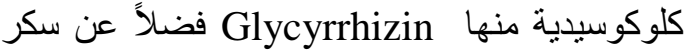
الكلوكوز وتبلغ حـلاوة المادة فيه 40 مرة ضعنف

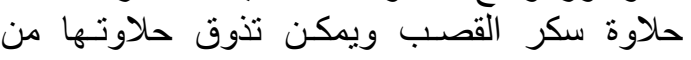

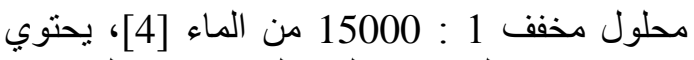

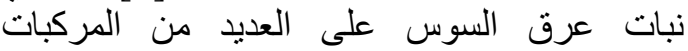

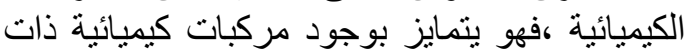

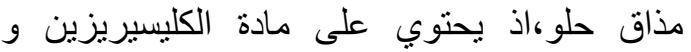

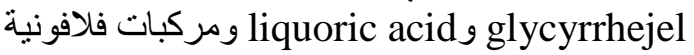

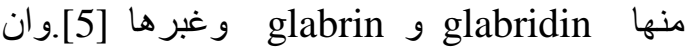
الكليسيريزين وحامضه الهم مكونين في عرق السوات السوس

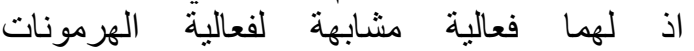
السترويدية،اذ انهما من الهرمونات النباتية التي تؤدي لهيت
ينتمي جنس الحمضيات Citrus الى العائلة السذبية Rutacea وتعد الحمضيات احد المدخلات

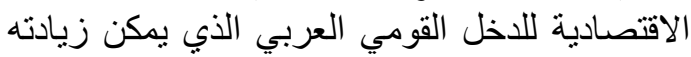

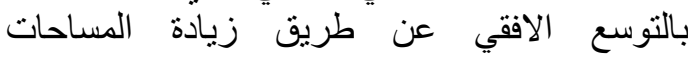

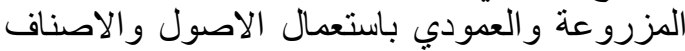
الجيدة و الطر ائق العلمية الحديثة في خدمة المحصول والاصن

Citrus (Sour orange) ويعد الأنارنج aurantium L.

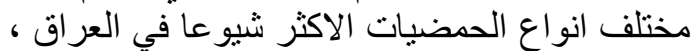

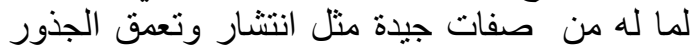

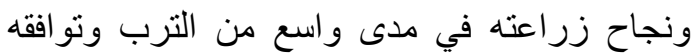

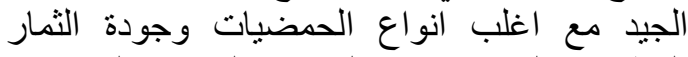

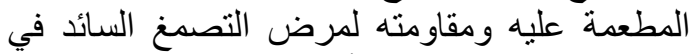

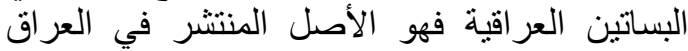
و المفضل من قبل الصحاب البساتين. فالئ الما الليمون الحامض Citrus limonum فيتمايز بانه يقاوم لحد ما الظروف المناخية المتطرفة اذ يقاوم درجات الحرارة العالية ويعاود النمو من جديد في في حالة التران التعرض الى درجات الحر ارة المنخفضة النعة 2]. 
غم في لتر من الماء المقطر و التركيز الثناني 2.5غم فئم في لترمن الماء المقطر و التركيز الثالث 4.5 فئ في في

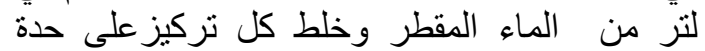

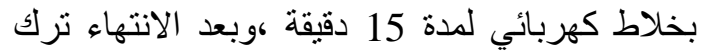

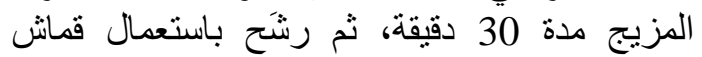
الململ (و هو قماش ابيض يشبه القماش الطبي يحتوي

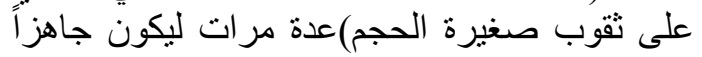
لنقع البذور به [7].

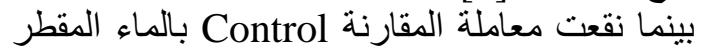
فقط ولبذور كلا النو عين . نفذت تجربة عاملية (2x4) وبخمسة مكرونة مكررات وقورنت المعدلات بحسب اختبار أقل فرق معنوي

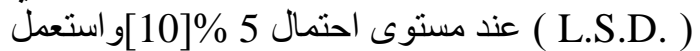
البرنامج SAS (2001) في التحليل الإحصائي ـ

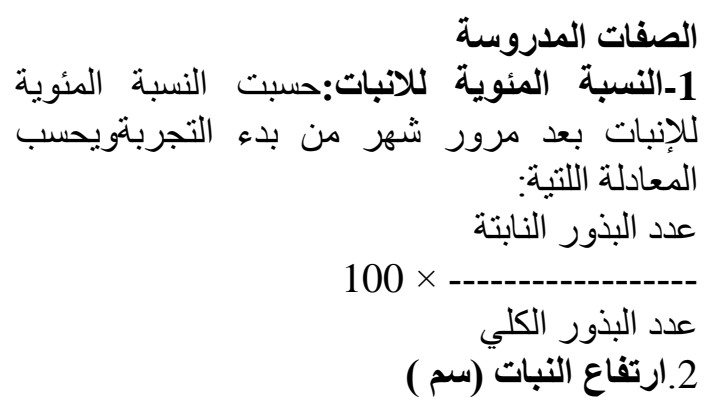

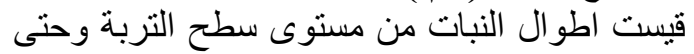

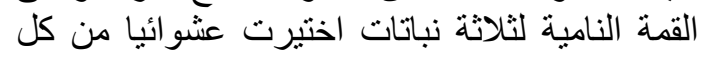

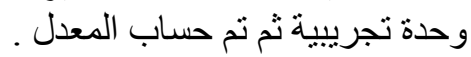
3.قطر الساق (سم)قيس قطر الساق باستعمال القدمة

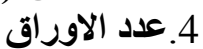
5. طول الجذر(سم) قيست الاوت ال الجذور من مستوى الجئ

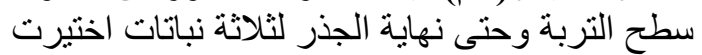

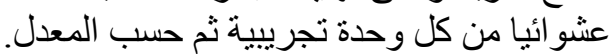

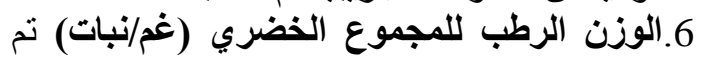

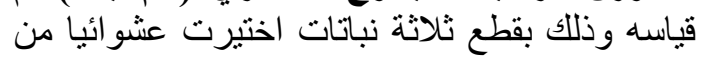

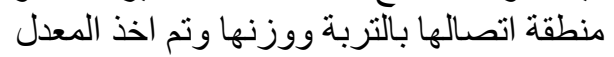

\section{النتائج والمناقثنة:} 1 - النسبة المئوية لإنبات البذور اظهرت نتائج الجدول ( 1 الإنبات الذون تفوق شتلات النارنج

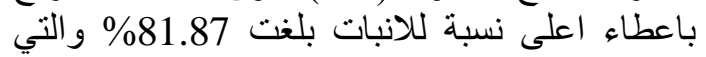

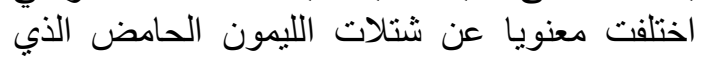

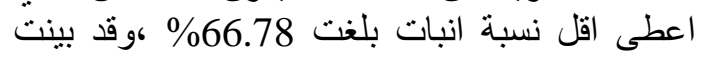

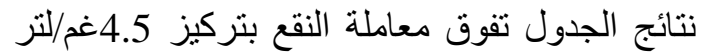

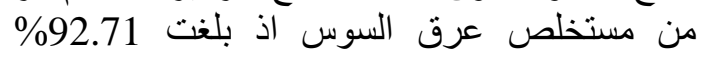

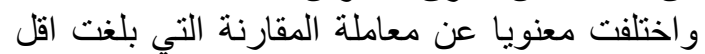

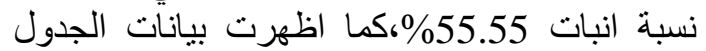

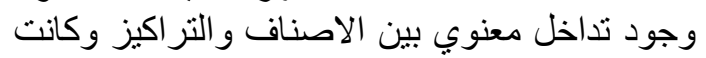
اعلى قيمة للتداخل عند النقع بتركيز

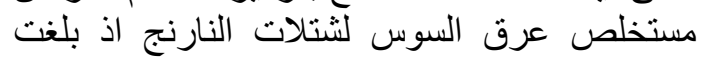
\% $\% 96.14$
الى زيادة تكوين البروتبنات لذلك ترفع من معدل النمو [6] زبادة وقد يسلك المستخلص سلوك الجبرلين في تأثيره

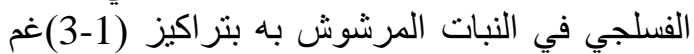

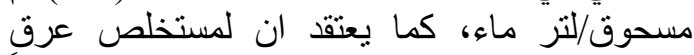

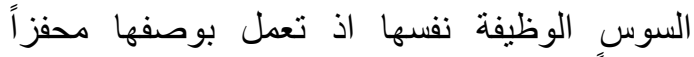

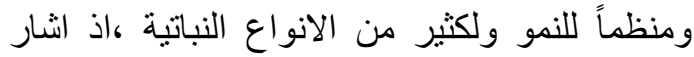
[7][الى ان عمل مستخلص عرق النير السوس مشابه

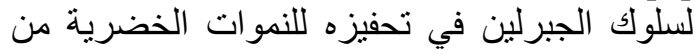
البراعم الساكنة، ويعمل على فيلى زيادة استطالة و انقسام

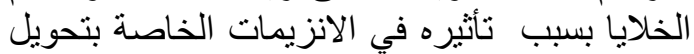

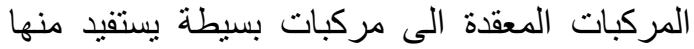

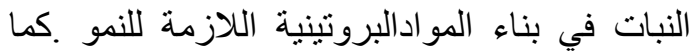

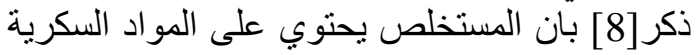

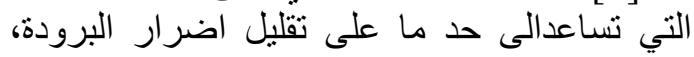
بسبب زيادة المواد الصلبة الذائبة في الخلايا النباتية النية و التي تزيد من مقاومة النبات لاضر التباد التها فيا.

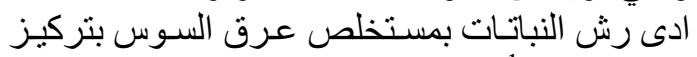

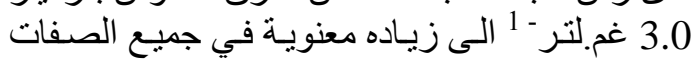

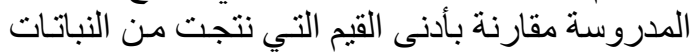

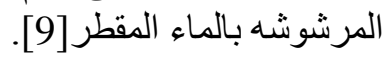
وبناءً على توصيات البحوثة البهر السابقة ومنها [7] التي

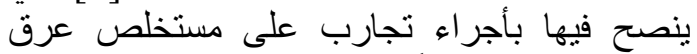

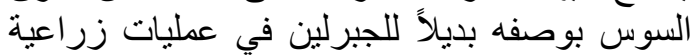
اخرباءت فكرة نقع بذور الحمضيّات به به وتعد عملية

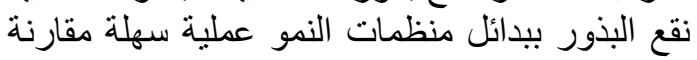

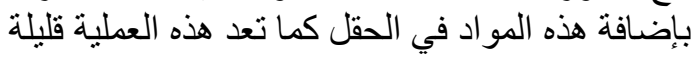

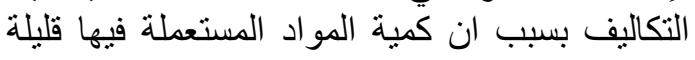

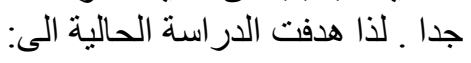

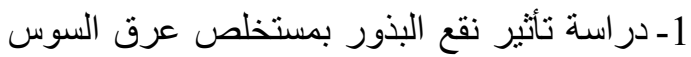

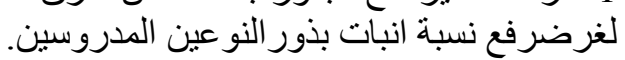

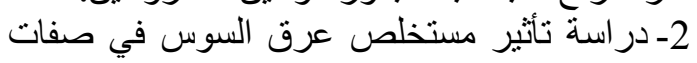
النمو الخضري للشتنات الناتجة .

اجري هذا البحث في ظلة خشئ خيبة تابعة لمشتل جامعة بغداد للمدة من ألار ولغاية ايلول 2013.

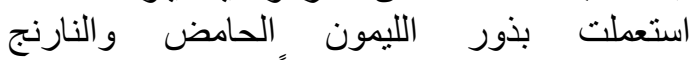
والمستخرجة من الثمارحديثاً اذ الذ غسلت بمادة Rizolex-T 50\% WP

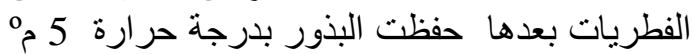

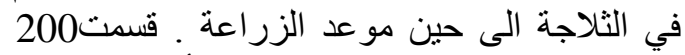
بذرة من كلا النوعين إلى اربعة الزعام أقسام استبعد

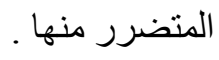

تحضير المستخلص المائي لمسحوق عرق السوس المس

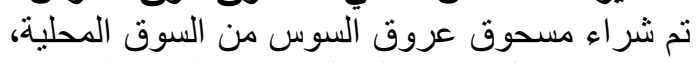

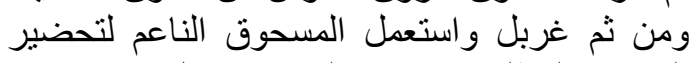
التراكيز المطلوبة ،حضَر التركيز الاول باذابة 0.5 
جدول (3) تأثير التنقيع بمستخلص عرق السوس في قطر الساق تائ

\begin{tabular}{|c|c|c|c|}
\hline المتوسط & (النارنج ) & $\begin{array}{l}\text { الليمضون } \\
\text { (ملم) }\end{array}$ & نوع النبات \\
\hline 0.46 & 0.48 & 0.45 & المقارنة \\
\hline 0.48 & 0.50 & 0.47 & 0.5 \\
\hline 0.50 & 0.53 & 0.48 & 2.5 \\
\hline \multirow[t]{2}{*}{0.53} & 0.57 & 0.50 & 4.5 \\
\hline & 0.52 & 0.47 & المتوسط \\
\hline للتداخل19.19 & للمعاملة 0.04 & للنوع0.13 & L.S.D \\
\hline
\end{tabular}

4 - عدد الأوراق /شتئة من الجدول (4 ) يلاحظ التأثير المعنوي لمعاملات

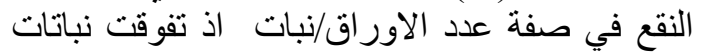

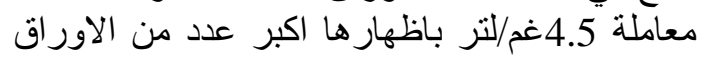

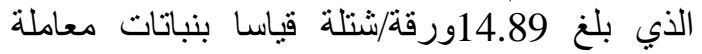
المقارنة التي اظهرت اقل عدد من الاوراق حيث بلغ بلغ المبات

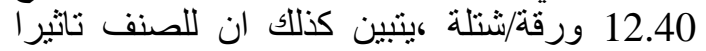

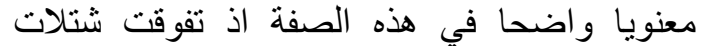

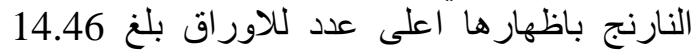
ورقة/شتلة والتي اختلفت معنويا عن شتلات التات الليمون الحامض، وكان التداخل بين معاملات النقع التعات

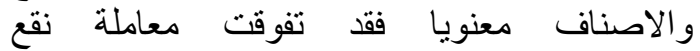

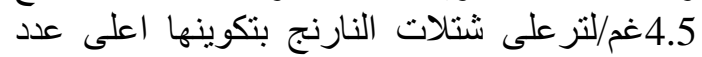

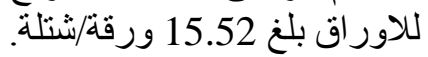
اتفقت هذه النتيجة مع ما وجده [12] من التع ان معاملة

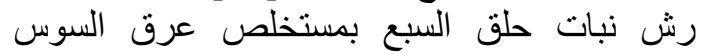
بتركيز 4 غم /لتر ادى الى زيادة ارتفاع النبات وعدد

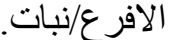

\begin{tabular}{|c|c|c|c|}
\hline المتوسط & (ورقة /شتنلة ) & (الليمقون/شئلة) & \\
\hline 12.40 & 12.55 & 12.24 & الفقارنة \\
\hline 13.70 & 14.44 & 12.96 & 0.5 \\
\hline 13.71 & 15.33 & 12.08 & 2.5 \\
\hline 14.89 & 15.52 & 14.27 & 4.5 \\
\hline & 14.46 & 12.89 & لالتوسط \\
\hline 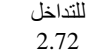 & للمعامة 1.10 & اللنوع1.21 & L.S.D \\
\hline
\end{tabular}

5. تاثير المعاملة بمستخلص عرق السوس في طول

اظظهرت نتائج الجدول (5) تفوقاً معنوياً في تر اكيز الجذر

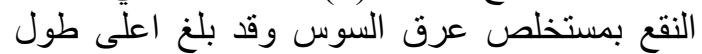
للجذر 31.3 سم عند النقع بتركيز 4.5 غم/لتر التر و اختلف معنويا عن معاملة المقارنة التي اظهرت الته

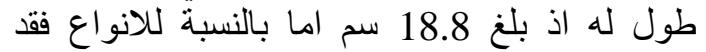

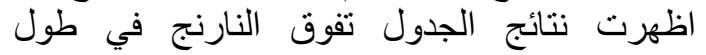

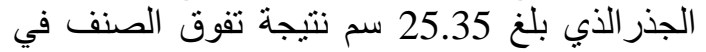
عدد الاوراق /نبات وزيادة عملية التمثيل الضوئئي

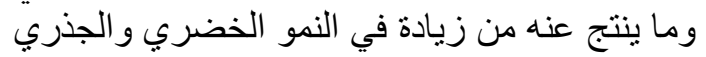
جدول(3) و(5 ).وكان للتداخل تاثير المعنويا في هذه الجن
جدول (1):تاثير نقع بذورالليمون الحامض والنارنج

في مستخلص عرق السوس في نسبة الانبات (\%) (1)

\begin{tabular}{|c|c|c|c|}
\hline \multirow[b]{2}{*}{ المتوسط } & \multicolumn{2}{|c|}{ النسبة المئوية للانبات (\% ) } & \multirow[t]{2}{*}{ نو البذو البذور } \\
\hline & النارنج & الحامضون & \\
\hline 55.55 & 66.67 & 44.44 & 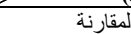 \\
\hline 67.01 & 78.47 & 55.56 & 0.5 \\
\hline 82.00 & 86.23 & 77.78 & 2.5 \\
\hline 92.71 & 96.14 & 89.29 & 4.5 \\
\hline & 81.87 & 66.76 & لمتوسط \\
\hline للتـاخل 8.94 & لالمعاملة 4.66 & 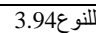 & L.S.D \\
\hline
\end{tabular}

2- ارتفاع النبات (سم)

يتضح من الجدول (2) اختلاف معاملات النقع فيما

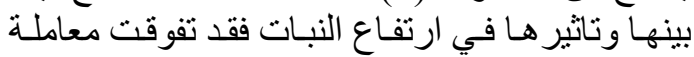

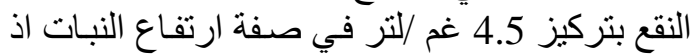

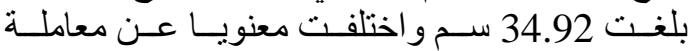
المقارنــة والتـي بلغت 29.23 سلغ 29. معنويا في صفة ارتفاع النبات فقد بلغ اعلى ارتفاع التفاع

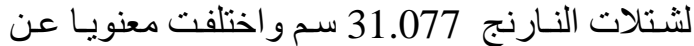
شتلات الليمون الحامض التي بلغت 29.69سم .

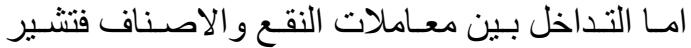

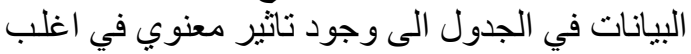

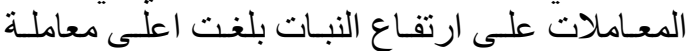

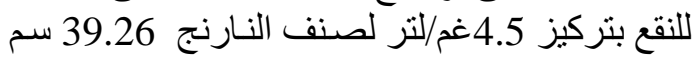

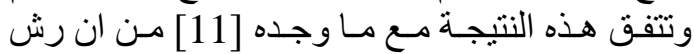

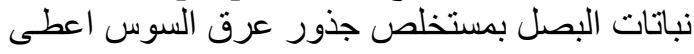
اعلى ارتفاع للنبات .

جذول (2) تأثير النقع بمستخلص عرق السوس في

\begin{tabular}{|c|c|c|c|}
\hline \multicolumn{3}{|c|}{ ارثفاع النبات } \\
\hline
\end{tabular}

3- تاثير المعاملة بمستخلص عرق السوس في قطر

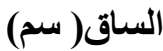

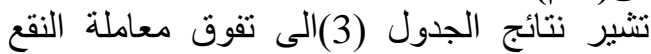
بمستخلص عرق السوس بتركيز 4.5 غم/لتر معنوفيا في صفة قطر الساق اذ بلغت 0.53 سم واختلفت

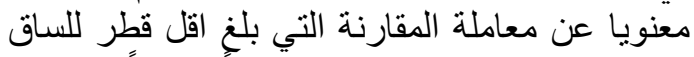

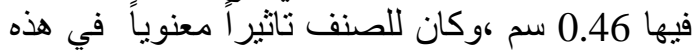

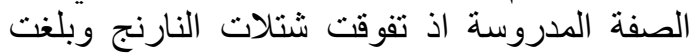

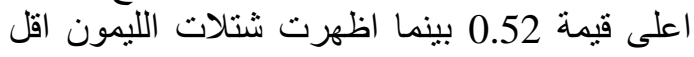

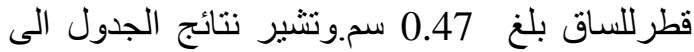

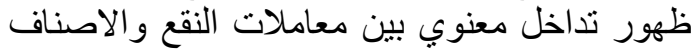

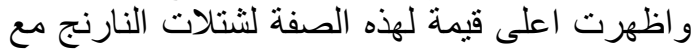
معاملة النقع بتركيز 4.5 غم/لتر وبلغ 0.57 سم. 


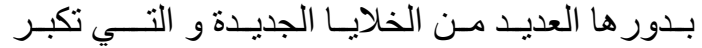

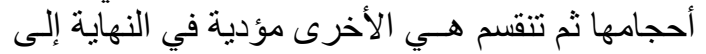

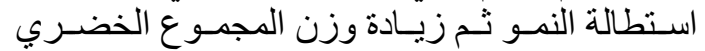

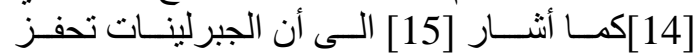
استطالة الخلايا ، اذ تؤدي الجبرلينات إلى زئل زيادة ليونة

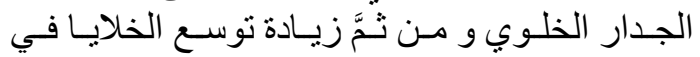

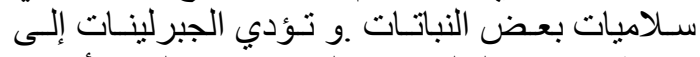
تنشيط الانقسام الخلوي في المرستيمات القميـة أو في

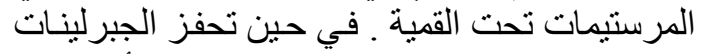

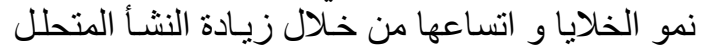

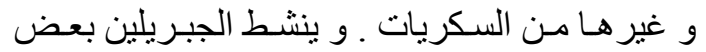
الجينات في كروموسومات الخلية و من ثم تؤدي إلى

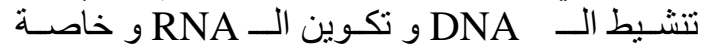

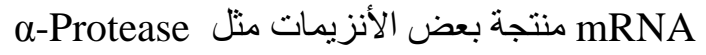
و و Ritronuclease amylase

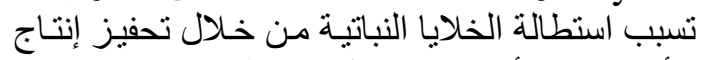

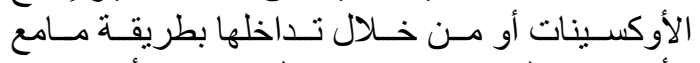

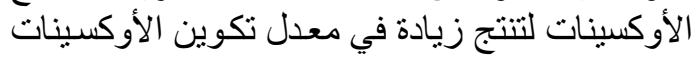

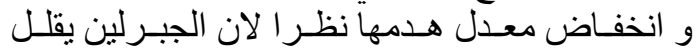

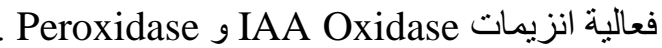

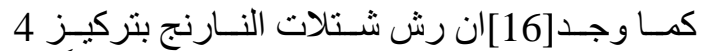
غم/لتر من مستخلص عرق السوس تفوق معنوياً في

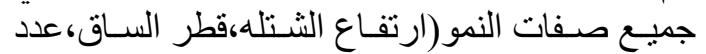

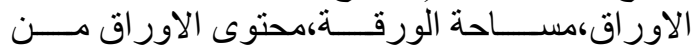

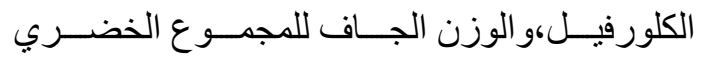

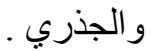

لقد جاءت هذه النتائج متماثية مع ما توصل إليه إليه

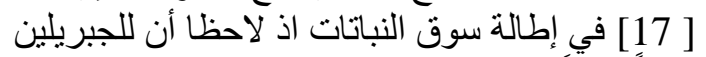

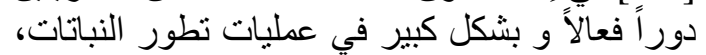

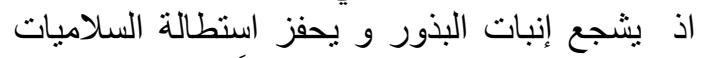

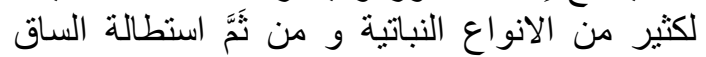

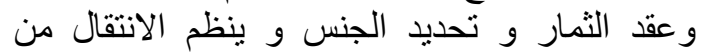

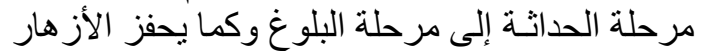

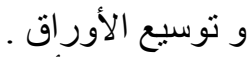
كما ذكر [17] أن شتـلات Enhances carambola 500, 250) المعاملــة بـالـ

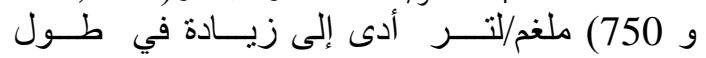

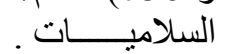

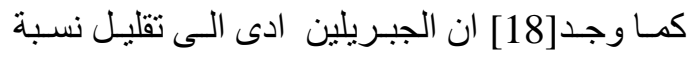

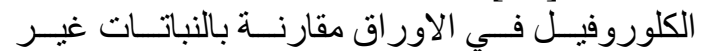
المعاملة .

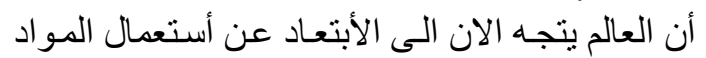

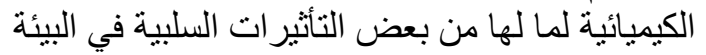

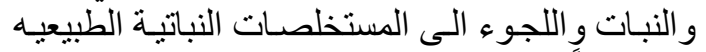

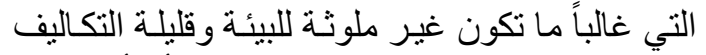

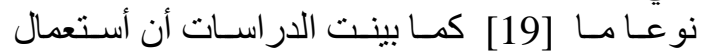

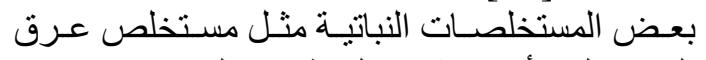

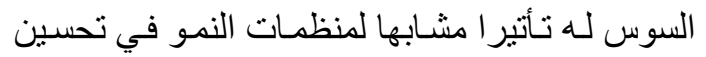

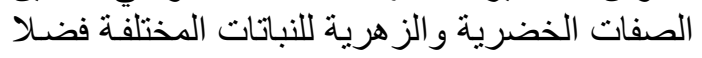

الصفة وقد بلغ اعلى قيمة له بمعاملة النقع 4.5 .5

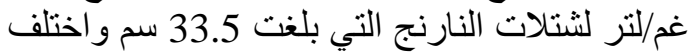
معنويا عن اقل طول للجذر عند معاملة المقارنة مع لأند

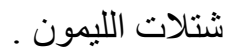

جدول (5) تأثير النقع بمستخلص عرق السوس في طول الجذر الرئيس

\begin{tabular}{|c|c|c|c|}
\hline المتوسط & (النارنج & الليمون الحامض & نوع النبات \\
\hline 18.8 & 19.4 & 18.2 & المقارنة \\
\hline 22.05 & 22.9 & 21.2 & 0.5 \\
\hline 25.0 & 25.6 & 24.4 & 2.5 \\
\hline \multirow[t]{2}{*}{31.3} & 33.5 & 30.1 & 4.5 \\
\hline & 25.35 & 23.47 & المتوسط \\
\hline اللتداخل 5.55 & اللمعاملة 3.12 & لللنوع 1.79 & L.S.D \\
\hline
\end{tabular}

6- تاثير المعاملة بمستخلص عرق السوس في الوزن الطري للمجموع الخضري

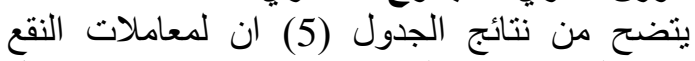

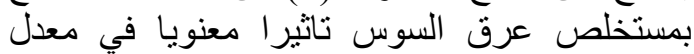
الوزن الطري للثتلات اذ بلغت اعلى قيمة لله 1.52

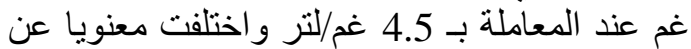
اقل قيمة وهي 0.38 غم في معاملة المقارنة.

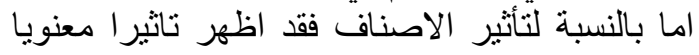
بين الاصناف وبلغت العلى قيمة له اله عند معاملة

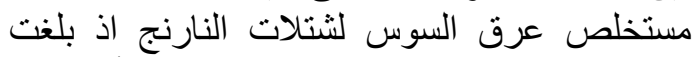

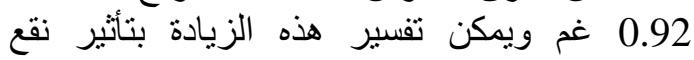

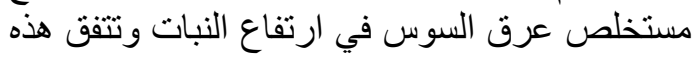

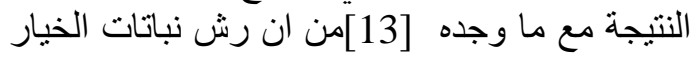
بمستخلص عرق السوس الدى الى الى زيادة الوزن ناتن الفيار

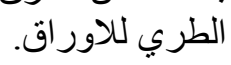

جدول (6) تأثير النقع بمستخلص عرق السوس في الوزن الطري للمجموع الخضرع الثري

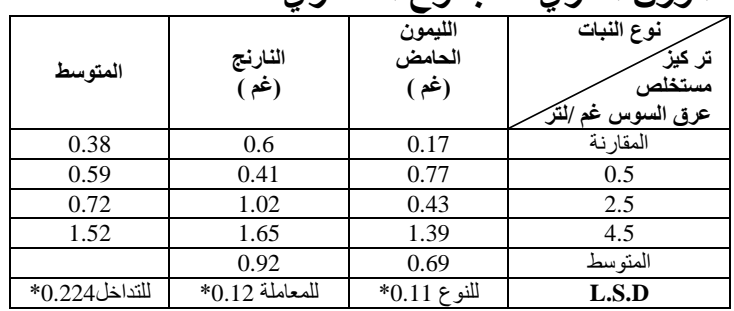

يمكن القول إن هنـاك اختلافاً في استجابة النمو

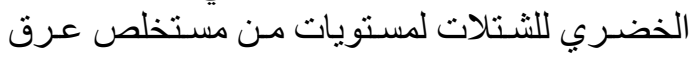

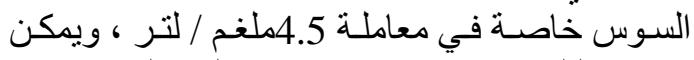

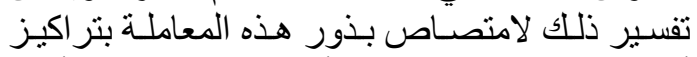

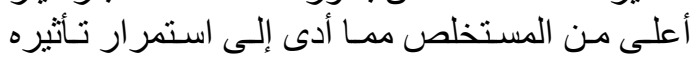

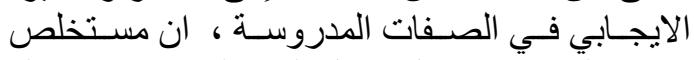

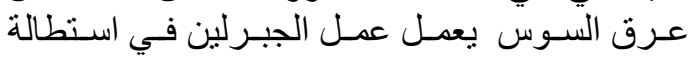

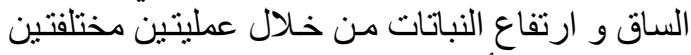

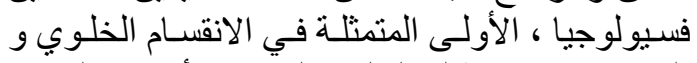

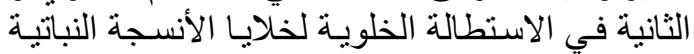
داخليا ، بمعنى إن الخلية يحدث فيها الانقسام معطية الانية 
[11] الخفاجي، اسيل محمد حسن هاتف.2010. تاثير

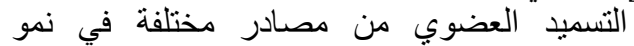

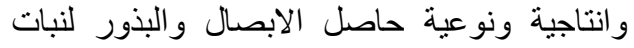

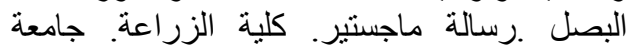

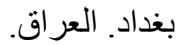

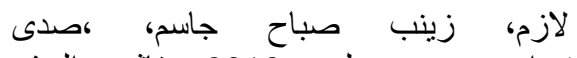

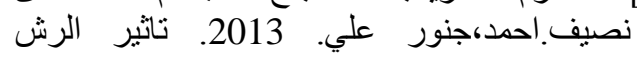
بمستخلص عرق السوس و الحلبة في النمو الخضري

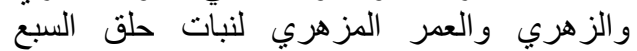
Antirrhinum majus L.

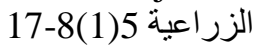

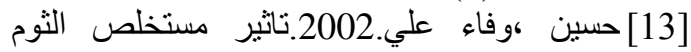
وجذور عرق السوس واليوريا في صفات والير النمو الخضري والزهري والحاصل والتصفات النوعية

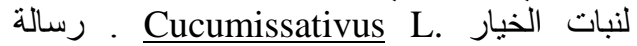
ماجستير .كلية الزر اعة.جامعة بغداد.العر اق.

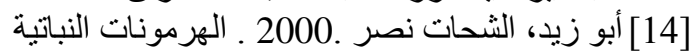
و التطبيقات الزراعية. الدار العربية للنشر و التوزيع النياتية

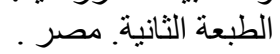

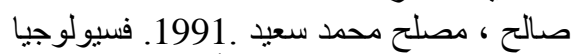

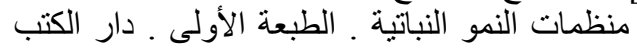

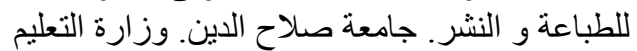

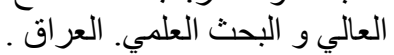

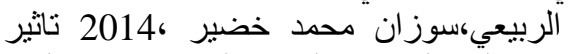
[16]

الرش بمعلق الخميرة الجافة النشطة ومستخلص

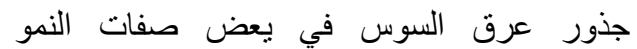
Citrus الخضري والجذري لشتنات النارنج Citrus aurantium aurantium 352-338(2)6.6 للعلوم الزر اعية

[17] Marler, Thomas E. and Michael V. Mickelbart. 1992. Application of GA4+7 to stem Enhances carambola Seedling growth. HortScience27: 122123.

[18] Puglisi, S. 2002. Use of plant growth regulators to enhance branching of Clematis SPP. Master of science. Department of Horticultural Scince. Virginia polytechnic instate and state university, Blacksburg. U.S.A.

الزرفي، مشتاق طالب حمادي.2009. تأثثر

الرش بالزنك ومستخلص جذور السوس في نمو

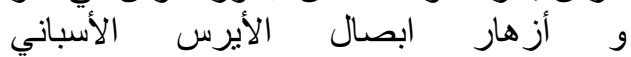
IrisxiphiumL. الزر اعه. جامعة الكوفة. العراق.

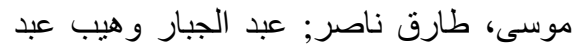

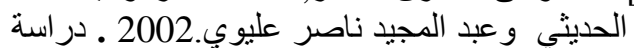

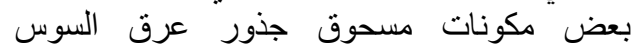

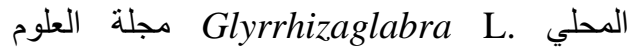
38-30: الزر اعية العر اقية .34 (4
عن ذللك احتو ائها على مجموعة كبيرة من العناصر و المو اد الغذائية [20].

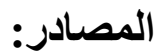

[1] حمد،محمد شهاب وفاروق فرج جمعة.(2000)تانثير التسميد الورقي في المحتوى المعدني ونسبة العقد

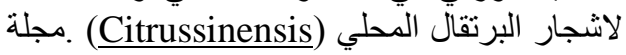

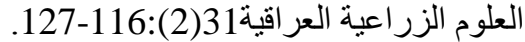

[2] الخفاجي- مكي علوان وسعيل عليوي عطرة وعلاء العزاء

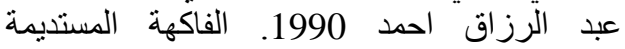
الخضرة- وزارة التعليم العالي والبحث العلمي-

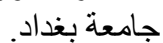

[3] الدروش، عامر خلف، 1975. دراسة تأثيثر الموقع وموعد الجني على المكونات الرئيسية للمادة الخام

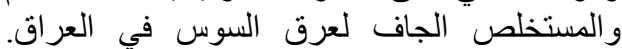

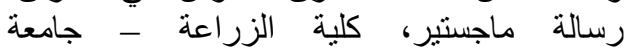
بغداد.العراق.

[4] حسين، فوزي طهقطب.1988. النباتات الطبية زر اعتها ومكوناتها. دار المريخ للنشر. جمهورية النيات مصر العربية.

[5] العجيلي ،ثامر عبد اللهزهوان.2005.تاثير الجبرلين GA3 وبعض المغذيات على انتاج الكليسيريزين الكيرلين Glycyrrhizin

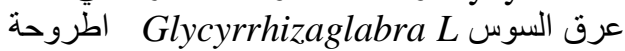
دكتور اه. كلية الزر اعة. جامعة بغداد.العراف.

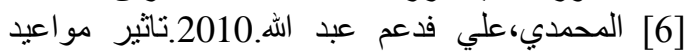

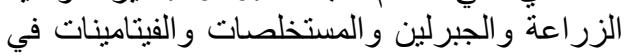

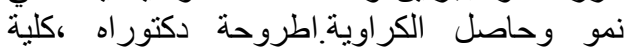
الزر اعة.جامعة بغداد.العر اق.

[7] المرسومي. حمود غربي خليفة، 1999. 19 دراسة الزية العوامل المؤثرة على صنفات النمو الخضري Allium cepa L. وحاصل البذور في البرة البصل أطروحة دكتور اه. كلية الزارعة - جامعة بغداد.

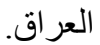

[8] محمد،عبد العظيم كاظم و اليونس ،مؤيد احمد.

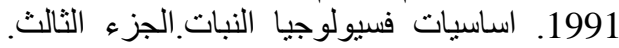
مطبعة دار الحكمة.جامعة بغداد.وزارة التعليم العالي التي و البحث العلمي .العراق.

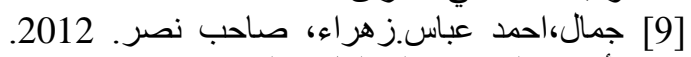

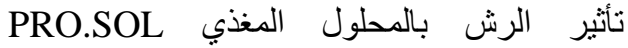
ومستخلص عرق السوس في بعض صفات النفات النمو

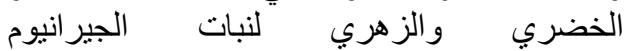
Pelargonium zonale L. الزر اعية.مجلد 4. عدد 1

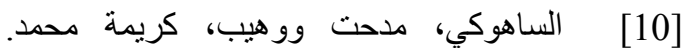
1990. تطبيقات في تصميم و تحليل التجارب دونة دار

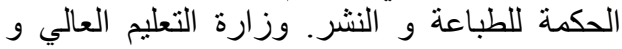
البحث العلمي كلية الزر اعة جامعة بغداد النماد 


\title{
Effect of soaking seeds Citrusaurantium and Citrus limonumat different concentrations of licorice extract on the percentage of germination and growth of seedlings
}

\author{
Fatima M. K. AL-Wailli \\ Department of Divants affairs, Presidency of Baghdad University \\ Received $28 / 4 / 2015$ \\ Accepted 16/9/2015

\begin{abstract}
:
This research was conducted under Lath house canopy of a nursery circumstances, Baghdad University for season 2013 in order to study the effect of soak lemon seeds sour orange with different levels of licorice concentrations extract

$(0,0.5,2.5$ and $4.5 \mathrm{~g} / \mathrm{l})$ for 24 hours in the percentage of germination and some recipes vegetative growth of seedlings the results outweigh the bitter orange seedlings and focus soak for licorice extract $4.5 \mathrm{~g} / 1$ significant superiority in most of the traits plant height, leaf number, root length, stem diameter, amounting to 31.077 $\mathrm{cm}, 14.46$ paper / plant, $25.35 \mathrm{~cm}, 0.52 \mathrm{~mm}$ respectively, which showed significant differences for the treatment of comparison which gave lower values.

Clear that the licorice extract biological effect similar to the effect of Al Gibberellin at germination lemon seeds, sour orange.
\end{abstract}

Key words: Seed germination, Citrusaurantium, Citrus limonum, seedling, Liqueric. 